ARTICLE

DOI: 10.1057/s41599-018-0164-y

\title{
Economic shifts in agricultural production and trade due to climate change
}

\author{
Luciana L. Porfirio (D) ${ }^{1}$, David Newth ${ }^{1}$, John J. Finnigan ${ }^{1} \&$ Yiyong Cai ${ }^{2}$
}

\begin{abstract}
In addition to expanding agricultural land area and intensifying crop yields, increasing the global trade of agricultural products is one mechanism that humanity has adopted to meet the nutritional demands of a growing population. However, climate change will affect the distribution of agricultural production and, therefore, food supply and global markets. Here we quantify the structural changes in the global agricultural trade network under the two contrasting greenhouse gas emissions scenarios by coupling seven Global Gridded Crop Models and five Earth System Models to a global dynamic economic model. Our results suggest that global trade patterns of agricultural commodities may be significantly different from today's reality with or without carbon mitigation. More specifically, the agricultural trade network becomes more centralised under the high $\mathrm{CO}_{2}$ emissions scenario, with a few regions dominating the markets. Under the carbon mitigation scenario, the trade network is more distributed and more regions are involved as either importers or exporters. Theoretically, the more distributed the structure of a network, the less vulnerable the system is to climatic or institutional shocks. Mitigating $\mathrm{CO}_{2}$ emissions has the co-benefit of creating a more stable agricultural trade system that may be better able to reduce food insecurity.
\end{abstract}

\footnotetext{
${ }^{1}$ Oceans \& Atmosphere. The Commonwealth Scientific and Industrial Research Organisation (CSIRO), Black Mountain Science and Innovation Park, Clunies Ross Street, Canberra, ATC 2601, Australia. ${ }^{2}$ Centre for Applied Macroeconomic Analysis, The Australian National University, JG Crawford Building, 132 Lennox Crossing, Canberra, ACT 0200, Australia. Correspondence and requests for materials should be addressed to

L.L.P. (email: Luciana.Porfirio@csiro.au)
} 


\section{Introduction}

nding world hunger whilst improving nutrition, promoting sustainable agriculture, and achieving food security, are key aspirations of the United Nations (UN) Sustainable Development Goals (SDG) (Griggs et al. 2013). In addition to expanding agricultural land area and intensifying crop yields (Fischer and Velthuizen, 2016), increasing the global trade of agricultural products is one mechanism that humanity has adopted to meet the nutritional demands of a growing world population (Fischer et al., 2014). However, human-induced climate change will affect the distribution of agricultural production (Lobell et al., 2008; Rosenzweig et al., 2014; Porfirio et al., 2016) and, therefore, food supply and global markets. The objective of this study is to explore the consequences of climate change for the world's agricultural trade network.

Achieving the second SDG of zero hunger will require: meeting shifting demands for agricultural products within a more affluent and growing population, mitigating the impacts of climate change on agricultural yields ( $\mathrm{Li}$ et al., 2009; Wheeler and von Braun, 2013; Nelson et al., 2014) and liberalising world agricultural markets (Cai et al., 2016). A growing population places additional pressure on the demand for food and agricultural commodities. The UN median population projection suggests that the world population will reach 9.8 billion in 2050. Between 2000 and 2010, approximately $66 \%$ of the daily kcal intake per person, about $1750 \mathrm{kcal}$, was derived from the four key commodities that are the focus of this study: wheat, rice, coarse grains and oilseeds (WHO -FAO, 2003). It is expected, in the short term at least, that $50 \%$ of dietary energy requirements will continue to be provided by these commodities and this will be produced in developing regions (WHO-FAO, 2003). Extrapolating from these numbers, an extra 10 billion kcal per day will be needed to meet global demands by 2050 . Understanding how climate change affects the production and trade of agricultural commodities is vital for ensuring the most vulnerable regions have access to a secure food supply.

Climate change has already influenced the patterns of agricultural production (Kang et al., 2009; Godfray et al., 2010; Nelson et al., 2010). About a third of the annual variability in agricultural yields is caused by climate variability (Howden et al., 2007). In addition, the interaction between climate variability and climate change threatens the sustainability of traditional agricultural systems (Hochman et al., 2017). The area of cropped land cannot change significantly in the future, if biodiversity and conservation goals are to be met (Watson et al., 2013). Improvements in agro-technologies have led to higher crop yields but extrapolation from past trends suggests that future increases in potential yield for most crops will be limited to $0.9-1.6 \%$ per annum (Fischer et al., 2014). While such changes in agricultural productivity have received a great deal of attention, the opportunities and risks brought about by changes in the global trade network have not been explored in depth even though trade is critical in meeting local shortfalls in production. Cooperative approaches to facilitating trade and enhancing food security, such as the Doha Development Round and the Bali and Nairobi packages, have largely failed due to disagreements among World Trade Organization members on the best strategies to achieve these goals (Droege et al., 2016).

Here we explore the consequences of climate change on the world's agricultural trade network from 2008 to 2059 under two IPCC Representative Concentration Pathways (RCPs). The RCP4.5 scenario limits the global temperature increase to $1.5^{\circ} \mathrm{C}$ relative to pre-industrial levels, while the RCP8.5 scenario results in global temperatures above $2^{\circ} \mathrm{C}$ by 2050 . To do this, we coupled seven Global Gridded Crop Models from the Agricultural Model Intercomparison and Improvement Project (AgMIP)
(Rosenzweig et al., 2014), which projects crop yields based on five Earth System Models, to a global economic model, which forecasts the economy to the end of 2050. The economic consequences of the biophysical changes in agricultural production are calculated using the Commonwealth Scientific and Industrial Research Organization (CSIRO) version of the Global Trade and Environment Model (GTEM-C) (Cai et al., 2015). GTEM-C is a dynamic general equilibrium and economy-wide model, capable of projecting trajectories for globally-traded commodities, particularly agricultural products. A predecessor of GTEM-C, called the Global Trade and Environment Model (Pant, 2007), was used in Nelson et al. (2014) to analyse the economic consequences of climate change effects on agriculture.

\section{Methods}

General modelling framework and past applications. The GTEM-C model was previously validated and used within the CSIRO Global Integrated Assessment Modelling framework (GIAM) to provide science-based evidence for decision and policy making. For example, alternative greenhouse gas (GHG) emissions pathways for the Garnaut Review, which studied the impacts of climate change on the Australian economy (Garnaut, 2011), the low pollution futures program that explored the economic impacts of reducing carbon emissions in Australia (Australia, 2008) and the socio-economic scenarios of the Australian National Outlook and project that explored the links between physics and the economy and developed 20 futures for Australia out to 2050 (Hatfield-Dodds et al., 2015). In the context of agroeconomics a predecessor of the GTEM-C model was used to analyse economic consequences of climate change impacts on agriculture. The GTEM-C model is a core component in the GIAM framework, a hybrid model that combines the top-down macroeconomic representation of a computable general equilibrium (CGE) model with the bottom-up details of energy production and GHG emissions.

GTEM-C builds upon the global trade and economic core of the Global Trade Analysis Project (GTAP) (Hertel, 1997) database (See Supplementary Information). Integrated modelling provides a unified framework to integrate transdisciplinary knowledge about human societies and the biophysical world. This approach offers a holistic understanding of the energycarbon-environment nexus (Akhtar et al., 2013) and has been intensively used for scenario analysis of the impact of possible climate futures on the socio-ecological systems (Masui et al., 2011; Riahi et al., 2011).

Overview of the GTEM-C model. GTEM-C is a general equilibrium and economy-wide model capable of projecting trajectories for globally-traded commodities, like agricultural products. Natural resources, land and labour are endogenous variables in GTEM-C. Skilled and unskilled labour moves freely across all domestic sectors, but the aggregate supply grows according to demographic and labour force participation assumptions and is constrained by the available working population, which is supplied exogenously to the model based on the UN median population growth trajectory (UN, 2017). The simulations presented in this study were performed setting GTEM-C's accuracy at $95 \%$ levels. Global land area devoted to agriculture is not expected to change dramatically in the future; nevertheless, the GTEM-C model adjusts cropping area within the regions based on demand for the studied commodities.

As is proper when using a CGE modelling framework, our results are based on the differences between a reference scenario and two counterfactual scenarios. The reference scenario assumes 
RCP8.5 carbon emissions but does not include perturbations in agricultural productivity due to climate. The RCP8.5 counterfactual scenario results in an increase in global temperatures above $2{ }^{\circ} \mathrm{C}$ by 2050 relative to pre-industrial levels. The agricultural productivities in the reference scenario are internally resolved within the GTEM-C model to meet global demand for food, assuming that technological improvements are able to buffer the influence of climate change on agricultural production. For the two counterfactual scenarios presented here, we use future agricultural productivities obtained from the AgMIP database to change GTEM-C's total factor productivities of the four studied commodities. The counterfactual scenario with no climate change mitigation follows the RCP8.5 emission but includes exogenous agricultural perturbations from the AgMIP database. This is, changes in agricultural productivity rates were not internally calculated by GTEM-C but given by the AgMIP projections. The RCP 4.5 scenario with climate change mitigation assumes an active $\mathrm{CO}_{2}$ mitigation achieved by imposing a global carbon price, so that additional radiative forcing begins to stabilise at about $4 \mathrm{Wm}^{-2}$ after 2050 . The carbon mitigation scenario includes exogenously perturbed agricultural productivities as modelled by the AgMIP project under RCP4.5. The RCP4.5 scenario limits global temperature increase to $1.5^{\circ} \mathrm{C}$, relative to pre-industrial levels.

The Earth System Models (ESMs) we use represent a wide cross-section of climate models from CMIP5, with a range of transient and equilibrium climate sensitivities between 1.3-2.5 and $2.44-4.67 \mathrm{~K}$, respectively, consistent with the assessed likely range from all CMIP5 climate models of 1.1-2.5 and 2.08-4.67 K, respectively. Climate projections from the ESMs are used to force a set of Global Gridded Crop Models (GGCM) (Nelson et al., 2014). These models were systematically compared in AgMIP (Rosenzweig et al., 2014) and they take into account crop responses to atmospheric $\mathrm{CO}_{2}$ concentrations as well as responses to water, temperature and nutrient stresses (Rosenzweig et al., 2014). Agricultural productivities within GTEM-C were exogenously forced with projections from the AgMIP database.

The current version of GTEM-C uses the GTAP 9.1 database. We disaggregate the world into 14 autonomous economic regions coupled by agricultural trade. Countries of large economic size and distinct institutional structures are modelled separately in GTEM-C, and the rest of the world is aggregated into regions according to geographical proximity and climate similarity. In GTEM-C each region has a representative household. The 14 regions used in this study are: Brazil (BR); China $(\mathrm{CN})$; East Asia (EA); Europe (EU); India (IN); Latin America (LA); Middle East and North Africa (ME); North America (NA); Oceania (OC); Russia and neighbour countries (RU); South Asia (SA); South East Asia (SE); Sub-Saharan Africa (SS) and the United States of America (US) (See Supplementary Information Table A2). The regional aggregation used in this study allowed us to run over 200 simulations (the combinations of GGCMs, ESMs and RCPs), using the high performance computing facilities at CSIRO in about a week. A greater disaggregation would have been too computationally expensive. Here, we focus on the trade of four major crops: wheat, rice, coarse grains, and oilseeds that constitute about $60 \%$ of the human caloric intake (Zhao et al., 2017); however, the database used in GTEM-C accounts for 57 commodities that we aggregated into 16 sectors (See Supplementary Information Table A3).

The RCP8.5 emission scenario was used to calibrate GTEM-C's business as usual case, as current $\mathrm{CO}_{2}$ emissions are tracking above RCP8.5 levels. A carbon price was endogenously calculated to force the model to match the lower RCP4.5 emissions trajectory. This ensured internal consistency between emissions scenarios and energy production (Cai and Arora, 2015). Climate change affects agricultural productivity, which leads to variations in agricultural outputs. Given the global demand for agricultural commodities, the market adjusts to balance the supply and demand for these commodities. This is achieved within GTEM-C by internal variations in prices of agricultural products, which determine the position and competitiveness of each region's agricultural sector within the global market, thus shaping the patterns of global agricultural trade.

Overview of the agricultural productivity in GTEM-C. We use the AgMIP (Rosenzweig et al., 2014; Elliott et al., 2015) dataset to modify agricultural productivities in GTEM-C. The AgMIP database comprises simulations of projected agricultural production based on a combination of GGCM, ESMs and emission scenarios. Here we perturb GTEM-C agricultural production of coarse grains, oilseeds, rice and wheat (the full list of sector modelled in GTEM-C can be seen in Supplementary Information Table A3). The crop yield projections for these four commodities were obtained from seven AgMIP GGCMs accessed in January 2016 (https://mygeohub.org/resources/agmip): EPIC, GEPIC, pDSSAT, LPJml, LPJ-GUESS, IMAGE-LEITAP and PEGASUS. The crop yield projections of the selected commodities are based on five ESMs: HadGEM2-ES, IPSL-CM5A-LR, MIROC-ESMCHEM, GFDL-ESM2M and NorESM1-M (see Table 1 in Villoria et al., 2016). Our scenarios are based on two RCP trajectories, 4.5 and 8.5 and the very optimistic carbon mitigation scenario, RCP2.6 (van Vuuren et al., 2011) was not included in our study for two reasons: first, the AgMIP database contains a limited number of simulations for the four analysed commodities for RCP2.6 compare to RCPs 4.5 and 8.5. Second, it would be necessary to include into GTEM-C a negative carbon emissions technology in order to achieve the first Shared Socio-economic Pathway that corresponds to the RCP2.6's $\mathrm{CO}_{2}$ emissions trajectory.

Mathematical characterisation of the trade network. To quantify the structural changes in the agricultural trade network, we developed an index based on the relationship between importing and exporting regions as captured in their covariance matrix. We represent the spectrum of the eigenvalues of this covariance matrix as the elements, $s_{i j}$ of a diagonal $14 \times 14$ matrix, where we have modelled 14 importing and exporting regions in our simulations. It is natural to interpret a rapidly converging spectrum as indicative of a trade network dominated by just a few importers and exporters while a flat spectrum of eigenvalues implies a network with many more equal actors. We capture this difference by the Shannon entropy of the eigenvalue spectrum and define the structural trade index as $S$. A smaller value of $S$ represents a centralised network structure, where export/import flows are dominated by just few regions; larger values of $S$ indicate a more distributed trading structure, where export/import flows are more uniformly distributed between all regions.

We tested if the $S$ index could capture historical shocks to the agricultural trade network by first applying our index to bilateral trade data for the period 1870-2014 from the Correlates of War Project Data Set version 4.0 (Barbieri and Keshk, 2016). Second, we applied the metric to the agricultural global trade data from the Food and Agricultural Organization (FAO) of the UN (FAOstat, 2016) for the period 1986-2010, focussing on the four selected commodities. Third, we applied the metric to the projections for the different ESMs and RCP scenarios based on the GTEM-C model.

The $\mathrm{N} \times \mathrm{N}$ import-export matrix $P$ encapsulates structural information about the global trade network, in this study $N=14$ regions. Each entry $p_{i j}$ in $P$ represents the value of exports from 


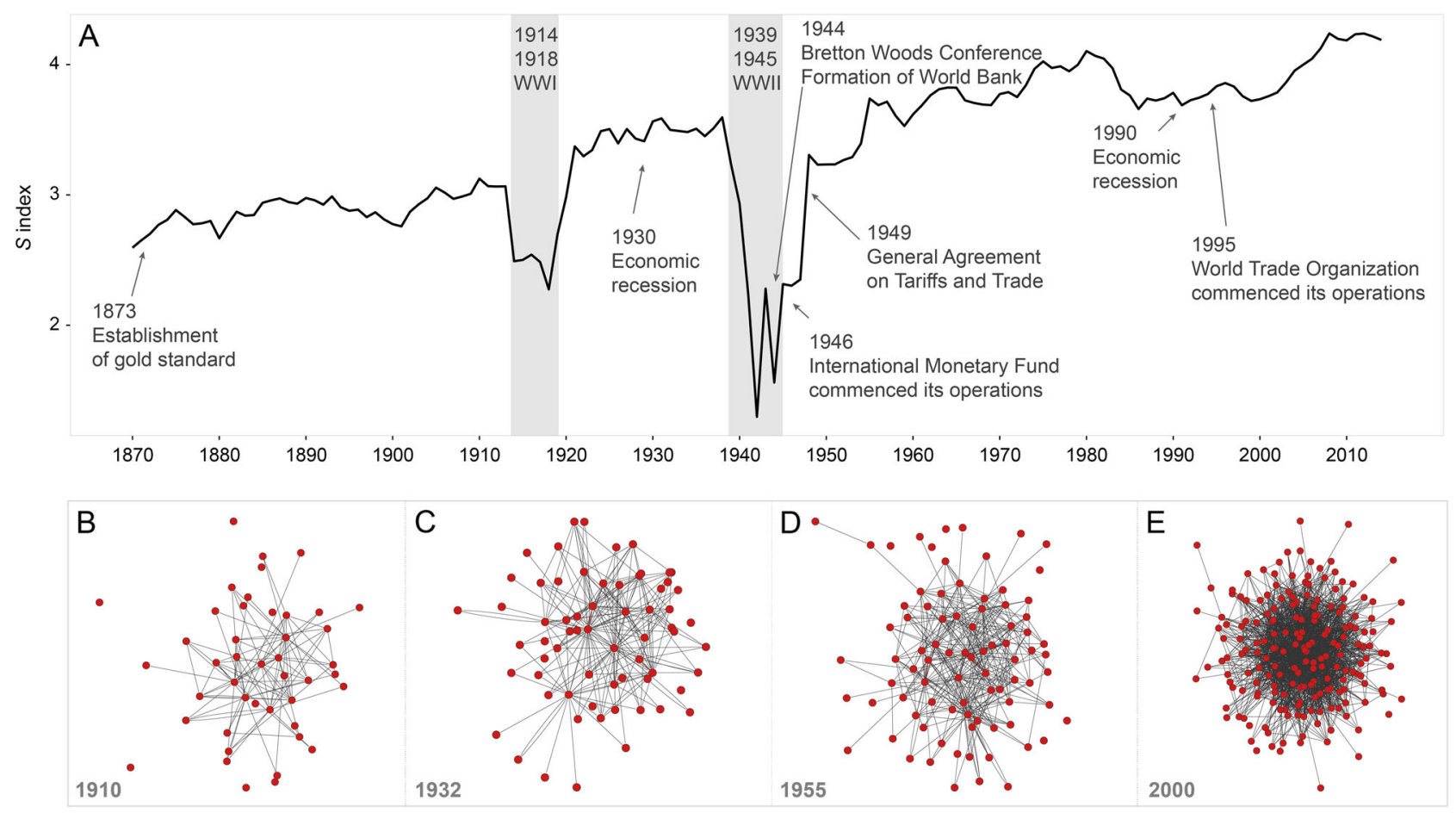

Fig. 1 Historical evolution of the structure of the global trade network for the period 1870-2014. a We illustrate the historical evolution of the global trade network by using bilateral trade data from the Correlates of War Project Data Set version 4.0 (Barbieri and Keshk, 2016). The bilateral trade dataset (Barbieri and Pollins, 2009) tracks total national trade and bilateral trade flows between states from 1870 to 2014 . We developed a metric (S) based on Shannon's entropy measure, which reflects the structure of the trade network by quantifying the underlying relationship between importing and exporting regions. Small values of the $S$ index represent a centralised network structure, where export/import flows are dominated by few regions, while larger values of $S$ characterise a more decentralised trading structure, where export/import flows are more uniformly distributed between all regions. $\mathbf{b}$-e Network plots characterising the structure of the global trading network from the beginning of the 20th century to the beginning of the 21st century

region $r_{i}$ to region $r_{j}$. Equally, each entry $p_{j i}$ represents the value of imports by region $r_{j}$ from region $r_{i}$. Hence the $i$ th row of matrix $P$ can be interpreted as an $\mathrm{N}$-dimensional vector of regions to which region $i$ exports with the components of the vector equal to the quantity of exports received from region $r_{i}$. Conversely, column $j$ of $P$ can be interpreted as an $\mathrm{N}$-dimensional vector of regions from which region $j$ imports with the components of the vector equal to the quantity of imports received from region $r_{i}$. If the trade network is regarded as a set of $\mathrm{N} \times \mathrm{N}$ edges or links, then the import-export matrix can be interpreted as the adjacency matrix of a directed graph with edges weighted by the trade in each direction between pairs of regions. Conventionally, we normalise the $p_{i j}$ values by the total volume of the global trade so that,

$$
\sum_{j-1}^{N} p_{i j}=1
$$

The resilience of the trade network to interruptions of supply by exporting countries or to inability to pay by importing countries is related to its relational structure.

A direct measure of the structure of the network is provided by the Shannon entropy (Simpson, 1949) of the matrix $P$ given by,

$$
H=-\sum_{j-1}^{N} p_{i j} \log _{2} p_{i j}
$$

This measure has been proposed for applications in both human and natural sciences (Phillips and Conviser, 1972) and (Bonchev and Buck, 2005). However, it is easy to see that $H$ is unaffected by any permutation of the $p_{i j}$ values so it cannot convey information about the relational structure (from where to where) of the trade network, only about its general structure. Theoretically, a distributed network is less vulnerable to disturbances. For example, to date soybeans are mostly exported by three regions, United States of America, Brazil and Argentina. If an increase in the frequency of strong ENSO events results in an increase of severe droughts or new pathogens affecting two of these main soybeans exporting regions, the global market would be severely affected.

To overcome the limitations of simply computing the Shannon entropy, $\mathrm{H}$ of the network, we propose a novel approach. The import/export matrix $P$ can be reconstructed from a set of simpler (rank 1) matrices $E_{i}$ formed from the singular vectors and scaled by the singular values.

$$
\begin{gathered}
P=U \Sigma V^{T} \\
P=E_{1}+E_{2}+\ldots E_{p} \\
E_{k}=\sigma_{k} \mu_{k} v_{k}^{T}
\end{gathered}
$$

Where ${ }^{T}$ denotes the transpose. Each column of $E_{k}$ is a multiple of $\mu_{k}$, the k'th row of $U$, the left singular vector and each row is a multiple of $v_{k}^{T}$, the transpose of the k'th column of $V$, the right singular vector. The component matrices are orthogonal to each other in the sense that

$$
E_{j} E_{k}^{T}=0, j \neq k
$$



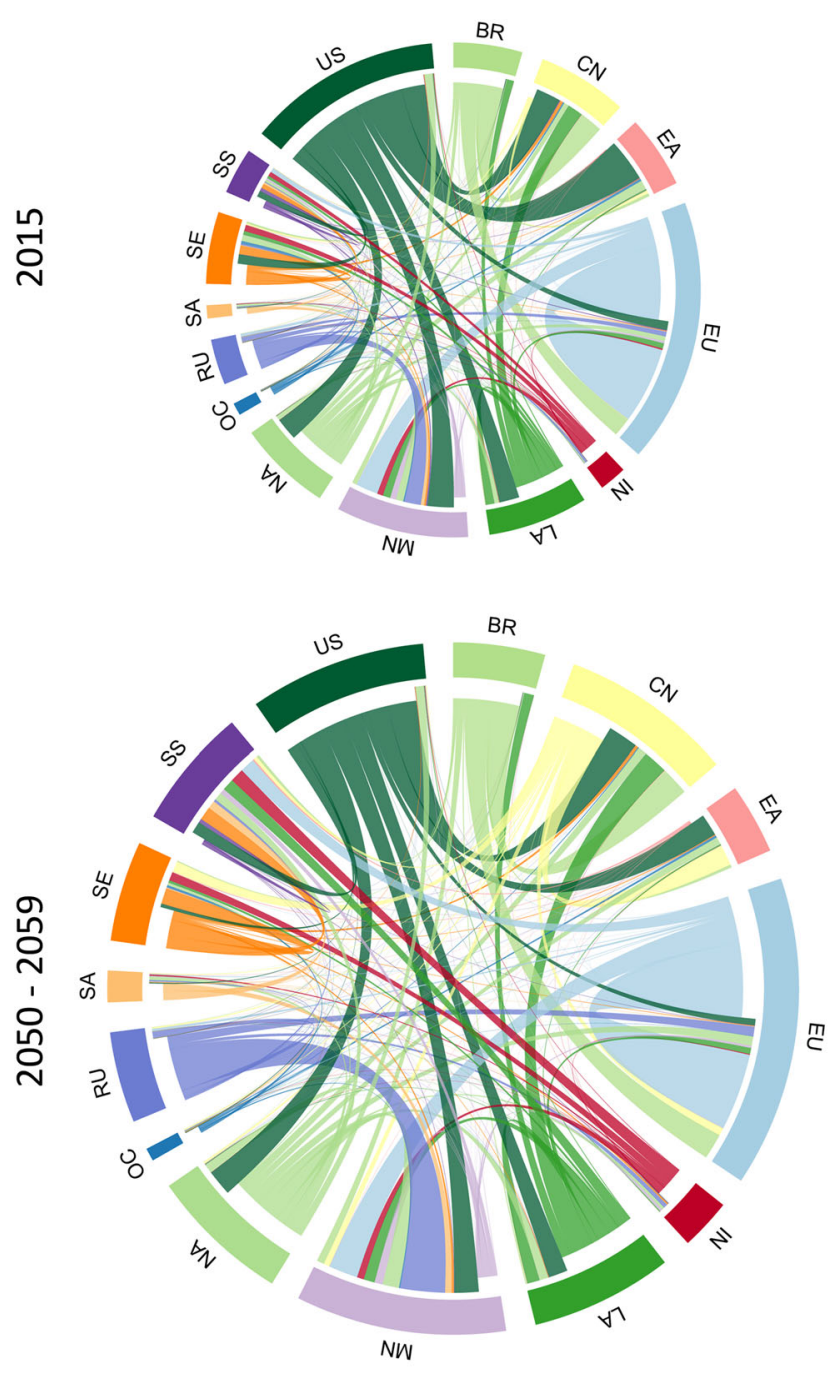

RCP 4.5
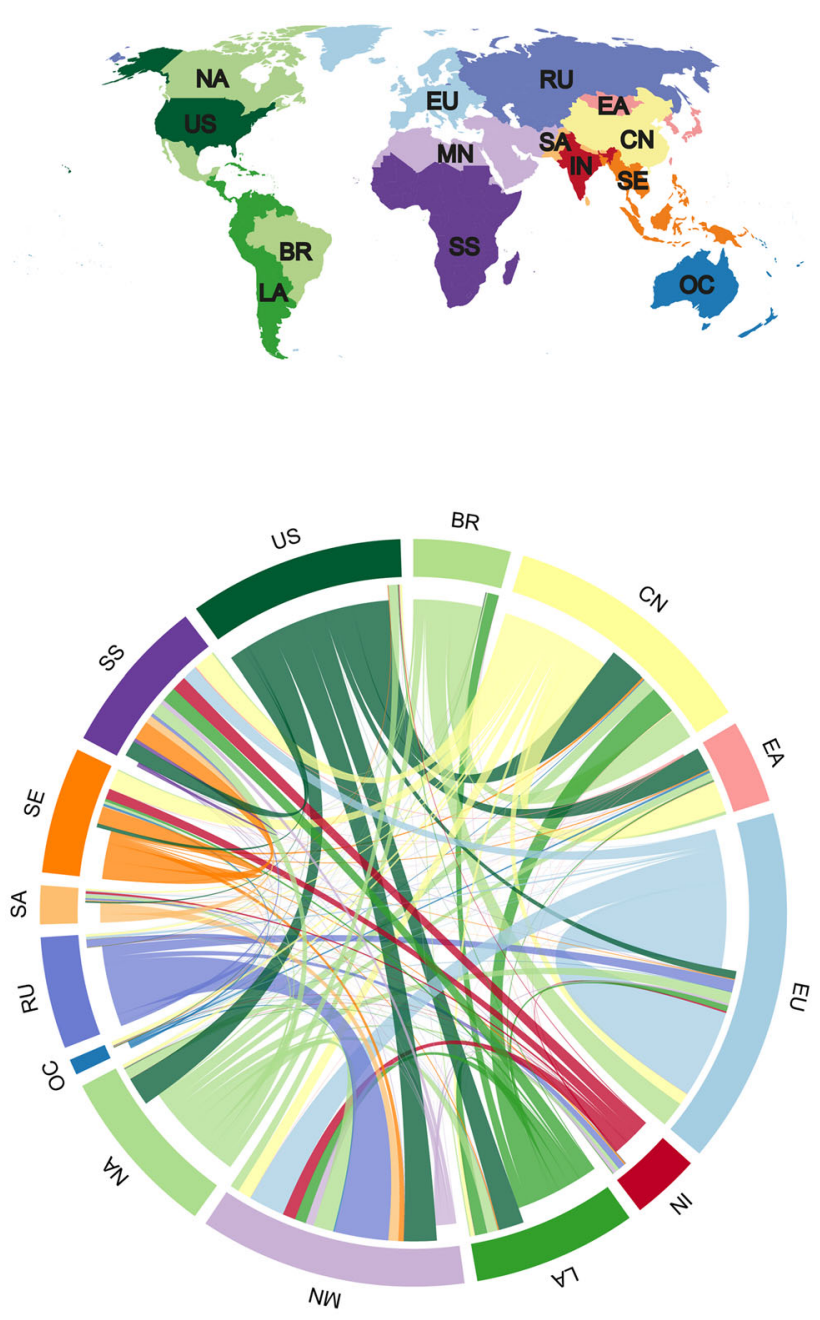

RCP 8.5

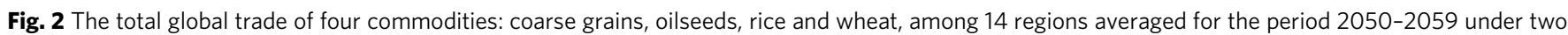
RCP scenarios. The' colours of the links in the circular plots correspond to the exporting regions. The circles are scaled according to the total global trade for the corresponding years. The base year (top left) shows total global trade in 2015. The RCP4.5 and 8.5 scenarios account for the effect of climate change on agricultural production and emission trajectories for RCP4.5 and 8.5, respectively. The CSIRO version of the Global Trade and Environment Model (GTEM-C), a dynamic Computable General Equilibrium model, was used to project the global economy. Agricultural productivities within GTEM-C were exogenously forced with data from the Agricultural Model Intercomparison and Improvement Project (AgMIP). This is, changes in agricultural productivity rates were not internally calculated by GTEM-C but given by the AgMIP projections. The regions are: Brazil (BR); China (CN); East Asia (EA); Europe (EU); India (IN); Latin America (LA); Middle East and North Africa (ME); North America (NA); Oceania (OC); Russia and neighbour countries (RU); South Asia (SA); South East Asia (SE); Sub-Saharan Africa (SS) and the United States of America (US)

The norm of each component matrix is just the singular value

$$
\left\|E_{k}\right\|=\sigma_{k}
$$

So the size of the contribution each $E_{k}$ makes to reproducing $P$ is just the associated singular value. This means that the singular values are the principal components.

From an information theoretic point of view, we are interested in how much information is needed to reconstruct $P$ to a given level of accuracy. If just the first few $E_{k}$ are enough to reproduce most of the $P$ correctly because they are dominant, then the information content of the network is small and its Shannon entropy, $H$ will be small. If all the $E_{k}$ are equally necessary, then its information content is maximal and its $H$ will be large. Hence an $H$ formed from the spectrum of sigmas produced by the singular value decomposition of $P$ is all we need.

We define the information entropy of the trade network therefore as,

$$
S=-\sum_{i j=1}^{N} \widehat{\sigma}_{i j} \log _{2} \widehat{\sigma}_{i j}
$$

where $\widehat{\sigma}_{i j}$ are singular values of $P$.

$S$ formed in this way will tend to large values when the importexport network is well connected with trade spread across all the regions. When the network simplifies and is dominated by a few large exporters and importers, $S$ values will be small and the network will be more connected. 


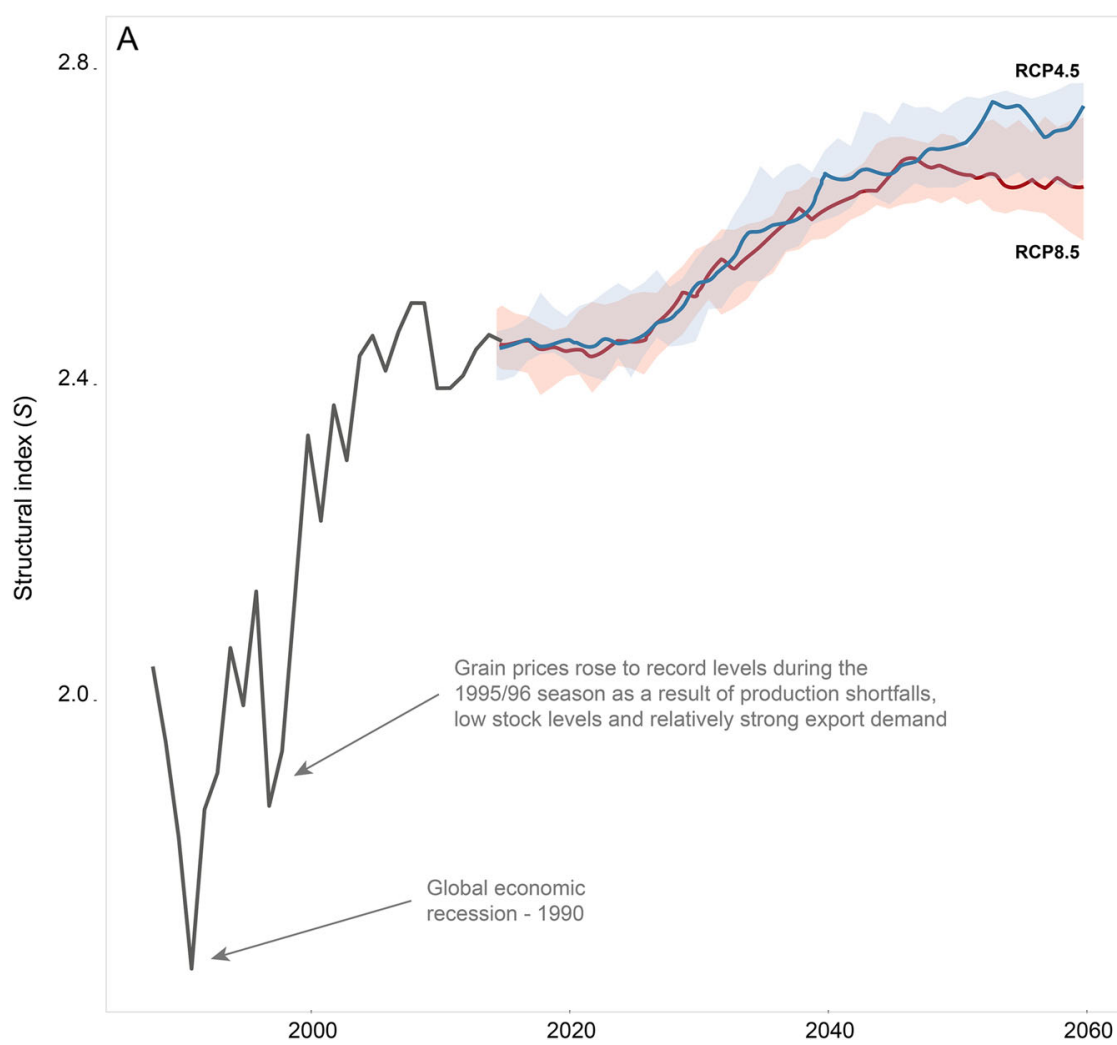

B

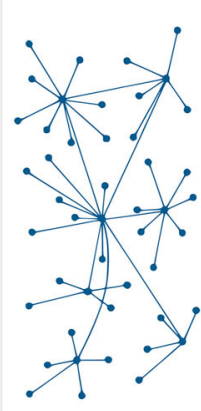

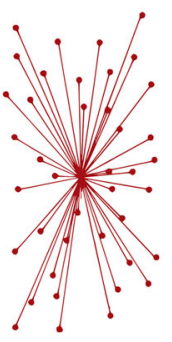

2020

2060

Fig. 3 Historical and projected changes in the structure of the global agricultural network under the RCP4.5 and RCP8.5 climate scenarios. A) We present a structural index S, based on Shannon's information entropy measure, that quantifies the underlying relationship between importing and exporting regions. Smaller values of the structural index represent a simpler trading network. Shown in grey is the historical trend of change in the global trading network based on data from FAO database from 1986 to 2013. From 2015 onwards the blue and red, curves represent the average values of changes in the global trade network for the two carbon emissions scenarios, RCP4.5 and RCP8.5, respectively, based on outputs from the CSIRO version of the Global Trade and Environment Model (GTEM-C). Higher values of the index represent a trading network that becomes more distributed. If the value of the structural index becomes smaller, the network becomes more centralised. The projections revealed that under RCP8.5 (red) the global trading structure becomes more centralised while under RCP4.5 (blue) $\mathrm{CO}_{2}$ mitigation scenario the global trading structure becomes more distributed. Shaded areas depict 25th and 75th values from the combination of Global Gridded Crop Models and ESM for each RCP scenario. B) Network plots characterising the structure of the global trading network from decentralised (top) to centralised (bottom)

\section{Results}

A new metric to quantify structural changes in the global trade network. We present a novel index called the structural $(S)$ metric, based on Shannon's information entropy measure. The $S$ metric measures the underlying relationship between importing and exporting regions. First, we tested the performance of the $S$ metric by using bilateral trade data from the Correlates of War Project Data Set version 4.0 (Barbieri and Keshk, 2016). The bilateral trade dataset (Barbieri and Pollins, 2009) tracks total national trade and bilateral trade flows between states from 1870-2014. Figure 1 shows the historical evolution and dynamics of the global trade system as characterised by the $S$ metric. Our results show a positive trend in the $S$ metric towards the end of the time series, indicating an increase of import/export interactions between the regions since 1870; that is, the trade network structure became more decentralised. Geopolitical and institutional events have had a strong influence in shaping the structure of the global trade network. See for example the effects of the First and Second World Wars on the structure of the global trade network (See Fig. 1). Each of these events reduced the number of connections in the global trade network; this is captured by lower values of the $S$ metric. Our index depicts the emergence of, for example, the International Monetary Fund and the General Agreement of Tariff and Trade, as corrective economic measures in the aftermath of the Second World War (See Fig. 1). Our results suggest that despite the economic recession in 1990 and later on in 2008, the structure of the global trade network has continued to diversify with more players involved.

Changes in the patterns of global agricultural trade due to climate change. We simulated patterns of global trade for 2050 for the four studied commodities: wheat, rice, coarse grains and oilseeds; under RCP4.5 and RCP8.5 (See Fig. 2). The circular plots in Fig. 2 are scaled according to the total global trade of the commodities analysed in our model ensemble for the year 2015 and averaged volume of trade for the period 2050-2059 for the two greenhouse gas emissions scenarios. For the reference, GTEM-C estimates that the value of total agricultural trade in the USA was 144 US\$ in 2015 (measured in 2007 US\$), this number closely matches data from the United States Department of Agriculture that reported a value of 136.7 US\$ for 2015 (United States Department of Agriculture, 2015a, 2015b).

The response of the global trade patterns to the different RCP emissions scenarios is uneven, reflecting different regional impacts of climate change on agricultural production and the uneven effect of a carbon price on regional economies, assuming no institutional changes. Climate change impact on agricultural production results in synergies and trade-offs for the regions. For example, in our scenarios, the US contributed $30 \%$ of global exports in 2015, while in the period 2050-2059 we project it will contribute only 10 or $11 \%$ under RCP 4.5 or RCP 8.5 , respectively. 
These falls in the USA's agricultural exports between 2015 and 2050 seem large; however, they align with projections of lower total factor productivities in the US due to climate change (Liang et al., 2017).

We found a significant difference in the number of exports from China to the rest of the world in our two scenarios. China is currently a net importer of the four studied commodities, i.e., this region contributed only about $1 \%$ of global exports in 2015 . Our simulations suggest that by $2050-2059$, China could become an exporter of some of these commodities. We project that the exports from China to the rest of the world will increase by $7.4 \%$ under RCP4.5 and 12.3\% under RCP8.5 (See Fig. 2). This increase in the proportion of exports from China is triggered by a positive response in agricultural productivity under the high carbon emissions scenario, i.e., China is a strong economy and contains a large landmass with multiple biomes suitable for growing the studied commodities. Brazil contributed $9.6 \%$ of exports of the four agricultural commodities in 2015 and is projected to share about $9.2 \%$ of the exports market under RCP 4.5 and $7.7 \%$ under RCP8.5 by the period 2050-2059 (See Fig. 2). Europe's contributions to exports were $20 \%$ in 2015 , and are projected to be $16.7 \%$ under RCP 4.5 and $15.5 \%$ under RCP 8.5 by the 2050 decade.

The simulations to 2050-2059 suggest that Sub-Saharan Africa will be the region with the largest increase in imports of coarse grains, oilseeds, paddy rice and wheat (See Fig. 2). Imports to Sub-Saharan Africa will double because the largest increase in human population in the next few decades will occur in this region, with a subsequent increase in the demand for food, which is accounted in our modelling framework. The response of global trade patterns to the different RCP emissions scenarios for other regions is uneven, reflecting different regional impacts of climate change on agricultural production and on regional economies.

Changes in the patterns of global agricultural trade. Our simulations based on GTEM-C suggest that there are changes in both the volume and patterns of agricultural trade. We used the $S$ metric to study changes in the patterns of agriculture trade, induced by regional variations in both the climate impacts on agricultural productivity and the economic impacts of unmitigated climate change and/or the cost of mitigation through an imposed carbon price. Small values of the $S$ metric represent a centralised network structure where export/import flows are dominated by few regions, while larger values of $S$ characterise a more decentralised trading structure where export/import flows are more uniformly distributed between all regions. The projected behaviour of $S$ through 2050 for all model realisations and ensembles are shown in Fig. 3. We also calculated the $S$ metric for a small historical global agricultural trade dataset from the FAO (FAOstat, 2016) that accounts for the four studied crops for the period 1986-2013 (grey line in Fig. 3). We observed two significant drops in the value of the index in that period (See Fig. 3). The first significant drop reflects the economic recession in the late 1980's that affected agricultural production. The second drop in 1995-1996 relates to climatically adverse conditions that resulted in agricultural production shortfalls. As a consequence, grain prices rose to record levels (Food and Agriculture Organization of the United Nations, 1996). The fluctuations in the $S$ metric during 1995-1996 (See Fig. 3) reflect a shortage in cereal production, which has removed some regions from trading these commodities, affecting the structure of the global agricultural trade network.

The simulations of the structure of the agricultural trade network from 2015 to 2059 (See Fig. 3) project a period of stability from 2015 to 2030, where the small differences in the climate responses of the two RCP scenarios over this period have little impact on agricultural production and therefore on trade. After 2030 both scenarios are affected by global warming, mostly through a reduction in agricultural production, which, under the framework of the dynamic global economic model is buffered by an increase in the amount of agricultural trade. This is captured by our index as an increase in the value of the $S$ metric. After 2040 we enter a phase where the two scenarios diverge, driven by the increasing differences in the climate response to the carbon emissions and increasing differences in the regional economic impacts of mitigating (RCP4.5) or not mitigating (RCP 8.5) GHG emissions. The global agricultural trade structure remains stable under RCP4.5, as climate affects agricultural production to a lesser degree than under RCP8.5, where agriculture is heavily impacted with a shortfall in production of key commodities. Under RCP 8.5 the global trade network becomes more centralised (showing smaller values of the $S$ metric). Hence, under RCP8.5, just a few regions may dominate export markets of the four commodities, while under RCP 4.5 more regions may be involved in the global trade as either importers or exporters.

\section{Discussion and outlook}

Some caveats need to be acknowledged. It should be noted that our modelling and analysis did not consider other extreme socioeconomic events, such as a recession or shift in geopolitical regimes, life expectancy or illiteracy rates, among others. Adding these considerations would be feasible and would provide a range of different scenarios. However, the focus of this paper is to assess the impacts of climatic change on agricultural production and, therefore, global agricultural trade; and we aimed to develop a metric capable of characterising and quantifying such a complex structure. Therefore, as a first attempt we decided to isolate the biophysical component, climate change and agricultural production, from other impacts so its mechanism could be fully understood. In the same way, we can test if it is possible to achieve the RCP2.6 scenario by incorporating negative emissions technologies into GTEM-C. For this to happen, it will require large breakthrough in carbon sequestration technology and significant land use change. These potential scenarios may yield interesting results; however, they depart from our main goal, which was to explore and understand the consequences of climate change for the world's agricultural trade network.

It is important to make one caveat regarding our use of GTEMC. The model parameters are estimated and calibrated against historical data. Economic data for many countries, particularly those outside the Organisation for Economic Cooperation and Development are very often of poor quality. Therefore, validation by post-diction and uncertainty analysis are critical when using the model. The current version of GTEM-C was validated in the context of the Australian National Outlook (Hatfield-Dodds et al., 2015). We have addressed the uncertainties in our methods by using the climate and crop model ensembles. Despite these limitations, GTEM-C provides a rigorous tool to analyse the energycarbon-environment nexus, and more importantly, a platform to integrate transdisciplinary knowledge about human societies and the biophysical world.

We have presented a comprehensive global assessment of the impact of future climate on the agricultural trade network. To our knowledge, this study is the first attempt to combine both the biological impacts of climate change on crop production with the economic impacts of climate change, both unmitigated or mitigated through a carbon price, on the ability of regions to grow, export or import staple food crops. We used the GTEM-C dynamic economic model to combine data from seven Global Gridded Crop Models from the AgMIP database, in which 
agricultural projections were based on five ESMs run for two RCPs, 4.5 and 8.5. Our year-to-year projections revealed that under RCP8.5 the structure of the global trade network becomes more centralised while under RCP4.5 it becomes more distributed. The results suggest that there is a synergistic interaction between mitigating $\mathrm{CO}_{2}$ emissions and obtaining a more distributed structure of the agricultural trade network and possibly promoting food security by having more regions able to participate in the trading market. Structural changes in the global trade network would have implications for biosecurity through the transport of commodities and potential new pathogens. A more distributed trade and production network could be more resilient to biological or economic impacts. Such considerations have a direct impact on each region's possibility of achieving the second United Nations' SDGs: zero hunger locally or contributing to global achievement.

Although there is apparent global willingness to transition to a low carbon economy (UNFCCC, 2015), current global carbon emissions are tracking above RCP8.5 (Friedlingstein et al., 2014). Our projections to 2050 suggest that the structure of agricultural trade under either RCP4.5 or 8.5 , will be significantly different from the current reality. A compelling result is that the quantity of agricultural commodities imported by Sub-Saharan Africa will at least double by 2050 . However, the two RCP scenarios present significantly different stories in terms of who the exporting regions could be, this is driven by shifts in regional climatic conditions that alter the existing agricultural system and the reaction of the various regions to climate impact and/or mitigation on their economies.

The agricultural productivities of the four selected crops show different responses to climate change. Rice, for example, is strongly affected by inter-annual climate variability, but overall rice yield has been increasing steadily since 1980's (Liu et al., 2016). Under the RCP8.5 climate scenario, rice yields are likely to decline by around 10\% (Zhao et al., 2017), but rice's yields will be less impacted than the other major crops, as wheat yields are projected to decrease by $\approx 22 \%$, maize by $\approx 27 \%$ and soybean by $\approx 11 \%$ under the RCP8.5 high $\mathrm{CO}_{2}$ emissions scenario. We note, however, that this divergence in yields between rice and other staples could be even higher if the crop models were to account for the future generation of rice cultivars that may be able to achieve higher yields with a reduction of methane emissions by about $10 \%$ (Jiang et al., 2017).

The stability and resilience to shock of a complex system, such as a trade network, is strongly conditioned by the structure of the network (Albert et al., 2000). Theoretically, the more distributed the network, the more resilient the system is to local and global failure. If the agricultural system is locally impacted, e.g., by a severe drought, flood or emergence of new pathogens, and crop production falls in a region as a result, a more distributed global trade network should be better able to fill the gap in agricultural production. The low $\mathrm{CO}_{2}$ emissions pathway (RCP4.5) leads to more stable and diversified agricultural production (Gerald et al., 2009) and as a consequence, the structure of the global trade network becomes more distributed. This suggests that a more distributed food trading network could be more resilient to shocks and better able to sustain future growing demand for food (May et al., 2008; Arinaminpathy et al., 2012) than the counterpart scenario, under RCP8.5.

Mitigating $\mathrm{CO}_{2}$ emissions has the unintended co-benefit of creating a more stable agricultural trade system that may be better able to reduce food insecurity (Porfirio et al., 2016; Zhao et al., 2017) and increase welfare by reducing social costs of carbon (Moore et al., 2017). Trading rules could potentially help to achieve transformative change in climate policy (Lininger, 2015). A strong economic structure (May et al., 2008; Arinaminpathy et al., 2012), with agile and robust policies, can help in mitigating climate impacts on agricultural production while transitioning to a low carbon economy.

\section{Data availability}

The results from the current study are available in the Dataverse repository: https://doi. org/10.7910/DVN/48BCMJ. The datasets analysed during the current study are from the following resources: https://www.gtap.agecon.purdue.edu/about/project.asp; and https:// mygeohub.org/resources/agmip

Received: 7 January 2018 Accepted: 13 August 2018

Published online: 04 September 2018

\section{References}

Akhtar M et al. (2013) Integrated assessment model of society-biosphere-climateeconomy-energy system. Environ Model Softw 49:1-21

Albert R, Jeong H, Barabási A (2000) Error and attack tolerance of complex networks. Nature 406:378-382

Arinaminpathy N, Kapadia S and May RM (2012) Size and complexity in model financial systems. Proc Natl Acad Sci U S A. https://doi.org/10.1073/ pnas. 1213767109

Australia C (2008) Australia's low pollution future: the economics of climate change mitigation http://lowpollutionfuture.treasury.gov.au/report/default. asp

Barbieri K, Keshk O (2016) Correlates of war project trade data set codebook, Version 4.0. http://correlatesofwar.org

Barbieri K, Pollins BM (2009) Trading data evaluating our assumptions and coding rules. Confl Manag Peace Sci 26(5):471-491

Bonchev D, Buck G (2005) Quantitative Measures of NetworkComplexity. In: Bonchev D., Rouvray D.H. (eds) Complexity in Chemistry, Biology, and Ecology. Springer,Boston, MA https://doi.org/10.1007/0-387-25871-X_5

Cai $\mathrm{Y}$ et al. (2015) A hybrid energy-economy model for global integrated assessment of climate change, carbon mitigation and energy transformation. Appl Energy 148:381-395. https://doi.org/10.1016/j.apenergy.2015.03.106

Cai Y, Arora V (2015) Disaggregating electricity generation technologies in CGE models: a revised technology bundle approach with an application to the U.S Clean Power Plan. Appl Energy 154:543-555. https://doi.org/10.1016/j. apenergy.2015.05.041

Cai Y, Bandara JS, Newth D (2016) A framework for integrated assessment of food production economics in South Asia under climate change. Environ Model Softw 75:459-497. https://doi.org/10.1016/j.envsoft.2015.10.024

Droege S et al. (2016) The trade system and climate action: ways forward under the Paris Agreement. Available at SSRN: https://ssrn.com/abstract $=2864400$ or $10.2139 /$ ssrn.2864400

Elliott J et al. (2015) The Global Gridded Crop Model Intercomparison: data and modeling protocols for Phase 1 (v1.0). Geosci Model Dev Copernic GmbH 8 (2):261-277. https://doi.org/10.5194/gmd-8-261-2015

FAOstat (2016) Statistical databases. http://www.fao.org/faostat/en/

Fischer G, Van Velthuizen H (2016) Global agro-ecological assessment for agriculture in the 21st century: methodology and results IIASA, Laxenburg, Austria

Fischer T, Byerlee D, Edmeades G (2014) Crop yields and global food security. ACIAR, Canberra, Australia

Food and Agriculture Organization of the United Nations (1996) The state of food and agriculture. Rome, FAO 1996: ISSN 0081-4539

Friedlingstein P et al. (2014) Persistent growth of CO2 emissions and implications for reaching climate targets. Nat Geosci 7(10):709-715. https://doi.org/ 10.1038 /ngeo 2248

Garnaut R (2011) The Garnaut review 2011: Australia in the global response to climate change. https://books.google.com.au/books?hl=en\&lr=\&id= UxJ7GzF11_0C\&oi $=$ fnd\&pg $=$ PR7\&dq $=+$ The + Garnaut + review +2011 : + Australia + in + the + global + response + to + climate + change\&ots $=$ hsHT1EM9ZO\&sig=Fpw4DWG0zfWU63a-QLhb9FhU500. Accessed 29 July 2015

Gerald C, Mark W, Jawoo K, Timothy RR (2009) Climate change-impact on agriculture and costs of adaptation 10.2499/0896295354

Godfray HCJ et al. (2010) Food security: the challenge of feeding 9 billion people. Science 327(5967):812-8. https://doi.org/10.1126/science.1185383

Griggs D et al. (2013) Policy: sustainable development goals for people and planet. Nature 495(7441):305-307. https://doi.org/10.1038/495305a

Hatfield-Dodds S et al. (2015) Australia is 'free to choose' economic growth and falling environmental pressures. Nature 527:49-53. https://doi.org/10.1038/ nature 16065 
Hertel T (1997) Global trade analysis: modeling and applications. Cambridge University Press

Hochman Z, Gobbett DL, Horan H (2017) Climate trends account for stalled wheat yields in Australia since 1990. Glob Change Biol 23(5):2071-2081. https://doi. org/10.1111/gcb.13604

Howden SM et al. (2007) Adapting agriculture to climate change. Proc Natl Acad Sci U S A. https://doi.org/10.1073/pnas.0701890104

Jiang Y et al. (2017) Higher yields and lower methane emissions with new rice cultivars. Glob Change Biol 23(11):4728-4738. https://doi.org/10.1111/gcb.13737

Kang Y, Khan S, Ma X (2009) Climate change impacts on crop yield, crop water productivity and food security? A review. Progress Nat Sci 19(12):1665-1674. https://doi.org/10.1016/j.pnsc.2009.08.001

Li YP et al. (2009) Climate change and drought: a risk assessment of crop-yield impacts. Clim Res 39(1):31-46. https://doi.org/10.3354/cr00797

Liang XZ et al. (2017) Determining climate effects on US total agricultural productivity. Proc Natl Acad Sci. https://doi.org/10.1073/pnas.1615922114

Lininger C (2015) Unilateral climate policies: the theoretical economic background. In Consumption-Based Approaches in International Climate Policy (pp. 53-61). Springer, Cham

Liu S-L et al. (2016) Yield variation of double-rice in response to climate change in Southern China. Eur J Agron 81(Supplement C):161-168. https://doi.org/ 10.1016/j.eja.2016.09.014

Lobell DB et al. (2008) Prioritizing climate change adaptation needs for food security in 2030. Science 319(5863):607-610

Masui $\mathrm{T}$ et al. (2011) An emission pathway for stabilization at $6 \mathrm{Wm}-2$ radiative forcing. Clim Change 109(1-2):59-76. https://doi.org/10.1007/s10584-011-0150-5

May RM, Levin SA, Sugihara G (2008) Complex systems: ecology for bankers. Nature 451(7181):893-895. https://doi.org/10.1038/451893a

Moore FC et al. (2017) New science of climate change impacts on agriculture implies higher social cost of carbon. Nat Commun 8(1):1607. https://doi.org/ $10.1038 / \mathrm{s} 41467-017-01792-x$

Nelson G et al. (2010) Food security, farming, and climate change to 2050: scenarios, results, policy options. https://books.google.com.au/books? $\mathrm{hl}=$ en\&lr $=\& \mathrm{id}=\mathrm{baD}-65 \mathrm{CCi} \_\mathrm{sC} \& \mathrm{oi}=$ fnd $\& \mathrm{pg}=\mathrm{PR} 11 \& \mathrm{dq}=$ Food + security, + farming, + and + climate + change + to $+2050:+$ Scenarios, + results, + policy +options\&ots $=$ NHHOhsAkmy\&sig $=$ MH8tfPZTh30PSt0tjLYSBTCc_kY. Accessed 8 Sept 2016

Nelson GC et al. (2014) Climate change effects on agriculture: economic responses to biophysical shocks. Proc Natl Acad Sci U S A. https://doi.org/10.1073/ pnas. 1222465110

Pant H (2007) GTEM: global trade and environment model. Australian Bureau of Agricultural and Resource Economics, Canberra

Phillips D, Conviser R (1972) Measuring the structure and boundary properties of groups: some uses of information theory (pp. 235-254). Sociometry. 10.2307/ 2786620 http://www.jstor.org/stable/2786620. Accessed 7 March 2016

Porfirio LL et al. (2016) Patterns of crop cover under future climates, Ambio. Springer, Netherlands, p 1-12. 10.1007/s13280-016-0818-1

Riahi K et al. (2011) RCP 8.5-A scenario of comparatively high greenhouse gas emissions. Clim Change 109(1-2):33-57. https://doi.org/10.1007/s10584-0110149-y

Rosenzweig C et al. (2014) Assessing agricultural risks of climate change in the 21st century in a global gridded crop model intercomparison. Proc Natl Acad Sci U S A. https://doi.org/10.1073/pnas.1222463110

Simpson EH (1949) Measurement of diversity. Nature 163(482):688-688. https:// doi.org/10.1038/163688a0

UN (2017) The world population prospects: 2017 revision, key findings and advance tables. New York https://esa.un.org/unpd/wpp/

UNFCCC (2015) Adoption of the Paris Agreement. Paris https:/unfccc.int/ resource/docs/2015/cop21/eng/109r01.pdf

United States Department of Agriculture (2015a) Agricultural trade. https://www. ers.usda.gov/data-products/ag-and-food-statistics-charting-the-essentials/ agricultural-trade/
United States Department of Agriculture (2015b) What is agriculture's share of the overall U.S. economy?. https://www.ers.usda.gov/data-products/chart-gallery/ gallery/chart-detail/?chartId $=58270$

Villoria NB et al. (2016) Rapid aggregation of global gridded crop model outputs to facilitate cross-disciplinary analysis of climate change impacts in agriculture Environ Model Softw 75:193-201. https://doi.org/10.1016/j.envsoft.2015.10.016

van Vuuren DP et al. (2011) RCP2.6: exploring the possibility to keep global mean temperature increase below $2{ }^{\circ} \mathrm{C}$. Clim Change 109(1):95. https://doi.org/ 10.1007/s10584-011-0152-3

Watson JEM, Iwamura T, Butt N (2013) Mapping vulnerability and conservation adaptation strategies under climate change. Nat Clim Change 3(11):989-994. https://doi.org/10.1038/nclimate2007. Nature Research

Wheeler T, von Braun J (2013) 'Climate change impacts on global food security.' Science 341(6145):508-13. https://doi.org/10.1126/science.1239402

WHO-FAO (2003) Global and regional food consumption patterns and trends. In: Diet, nutrition and the prevention of chronic disease. WHO Technical Report Series 916, p 1-17, World Health Organization

Zhao C et al. (2017) Temperature increase reduces global yields of major crops in four independent estimates. Proc Natl Acad Sci. 201701762; http://www.pnas. org/content/early/2017/08/10/1701762114.abstract

\section{Acknowledgements}

We thank our colleagues Dr Pep Canadell, Dr Rachel Law and Dr Helen Cleugh for their comments on an early version of the manuscript. This research was supported through funding from the Office of the Chief Executive Postdoctoral Fellowship (OCE) at the CSIRO.Data availabilityThe results from the current study are available in the Dataverse repository: https://doi.org/10.7910/DVN/48BCMJ. The datasets analysed during the current study are from the following resources: https://www.gtap.agecon.purdue.edu/ about/project.asp; and https://mygeohub.org/resources/agmip

\section{Additional information}

The online version of this article (https://doi.org/10.1057/s41599-018-0164-y) contains supplementary material, which is available to authorized users.

Competing interests: The authors declare no competing interests.

Reprints and permission information is available online at http://www.nature.com/ reprints

Publisher's note: Springer Nature remains neutral with regard to jurisdictional claims in published maps and institutional affiliations.

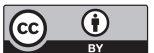

Open Access This article is licensed under a Creative Commons Attribution 4.0 International License, which permits use, sharing, adaptation, distribution and reproduction in any medium or format, as long as you give appropriate credit to the original author(s) and the source, provide a link to the Creative Commons license, and indicate if changes were made. The images or other third party material in this article are included in the article's Creative Commons license, unless indicated otherwise in a credit line to the material. If material is not included in the article's Creative Commons license and your intended use is not permitted by statutory regulation or exceeds the permitted use, you will need to obtain permission directly from the copyright holder. To view a copy of this license, visit http://creativecommons.org/ licenses/by/4.0/.

(c) The Author(s) 2018 